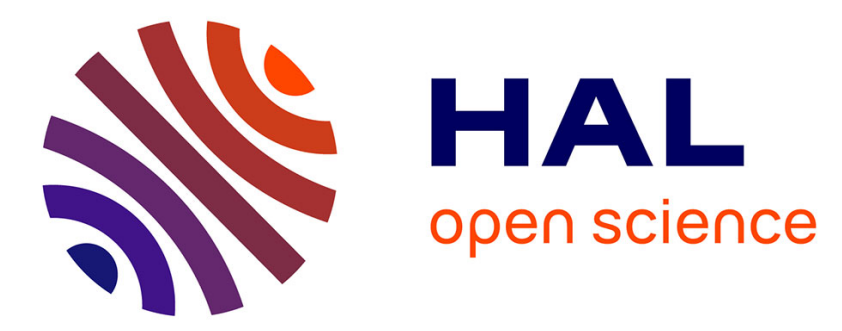

\title{
Non-adiabaticity in mantle convection
}

\author{
H.-P. Bunge, Y. Ricard, J. Matas
}

\section{To cite this version:}

H.-P. Bunge, Y. Ricard, J. Matas. Non-adiabaticity in mantle convection. Geophysical Research Letters, 2001, 28 (5), pp.879-882. 10.1029/2000GL011864 . hal-02046739

\section{HAL Id: hal-02046739 \\ https://hal.science/hal-02046739}

Submitted on 25 Jan 2021

HAL is a multi-disciplinary open access archive for the deposit and dissemination of scientific research documents, whether they are published or not. The documents may come from teaching and research institutions in France or abroad, or from public or private research centers.
L'archive ouverte pluridisciplinaire HAL, est destinée au dépôt et à la diffusion de documents scientifiques de niveau recherche, publiés ou non, émanant des établissements d'enseignement et de recherche français ou étrangers, des laboratoires publics ou privés. 


\title{
Non-adiabaticity in mantle convection
}

\author{
Hans-Peter Bunge \\ Department of Geosciences, Princeton University \\ Yanick Ricard \\ Department Sciences de la Terre, ENS-Lyon \\ Jan Matas ${ }^{1}$ \\ Department of Geology \& Geophysics, UC Berkeley
}

\begin{abstract}
Seismic observations indicate that Earth's lower mantle is homogeneous as revealed by smooth depth variations of the bulk sound velocity and Bullen's inhomogeneity parameter $\eta$ being close to one. Here we show with 3D spherical convection simulations that it should also be non-adiabatic because a significant proportion of mantle heat sources is internal. The computer simulations predict non-adiabaticity of 100-300 degrees for the lower mantle geotherm, with $\eta \sim 1.01$ implying that the temperature drop across the Core Mantle Boundary exceeds 1000 degrees.
\end{abstract}

\section{Introduction}

Seismic studies of free oscillations and body waves provide by far the most detailed information on the large-scale structure of the Earth [Giardini \& Woodhouse, 1987, van der Hilst et al., 1997]. Through much of the lower mantle they reveal smooth depth variations of seismic sound velocities, consistent with a homogeneous material under adiabatic self compression. Assuming adiabaticity Birch [1952] combined the Adams-Williamson equation with bulk sound velocity measurements to calculate a lower mantle density profile. Lower mantle density can also be obtained directly, with no assumption of adiabaticity, from the study of spheroidal low frequency normal modes. The agreement between body wave and normal data suggests that the lower mantle is nearly adiabatic [Masters, $1979 ;$ Dziewonski $\&$ Anderson, 1981] and modeled geotherms have been found in good agreement with the adiabat [Shankland $\mathcal{G}$ Brown, 1985], supporting a long-held view that vigorous convection of the deep mantle results in adiabaticity.

Geotherms derived from vigorously convecting fluid models of the mantle are also adiabatic provided that both internal and viscous heating can be neglected, with strongly superadiabatic temperature gradients concentrated into narrow thermal boundary layers near the surface and the core mantle boundary (CMB) [Jarvis \& McKenzie, 1980]. Strong internal heating, however, affects the geotherm giving rise to subadiabaticity in the interior of mantle convection cells even as the Rayleigh number approaches the convective

\footnotetext{
${ }^{1}$ Now at Department Sciences de la Terre, ENS de Lyon.
}

Copyright 2001 by the American Geophysical Union.

Paper number 2000GL011864.

0094-8276/01/2000GL011864\$05.00 vigor of the mantle [Tackley et al., 1994; Parmentier et al., 1994; Bunge et al., 1997]. The effect is important in mantle convection, where observational evidence suggests about $10 \%$ core heating in the overall heating budget of the mantle [Davies, 1988]. The physical reason for subadiabaticity is that material is slowly reheated by radioactivity while being entrained toward the surface by diffuse upwellings. Jeanloz $\&$ Morris [1987] estimate the impact of internal heating on the mantle geotherm and here we further investigate it in fully dynamic models. We demonstrate that subadiabaticity of 100-300 degrees may be expected in most of the lower mantle, while superadiabaticity in the bottom boundary layer should be confined to a layer of $\sim 500 \mathrm{~km}$.

\section{Convection models}

We model highly time-dependent convection in 3D spherical geometry [Bunge $\mathscr{G}$ Baumgardner, 1995]. Figure 1a shows a snapshot from an isoviscous reference calculation obtained assuming the mantle is compressible and heated purely from within. Material properties are identical to Bunge et al. [1997] and the Rayleigh number is $1.1 \times 10^{8}$ based on internal heating. The near surface and interior (cut-away) temperature fields are shown and the reference adiabat has been subtracted. Temperatures are subadiabatic as evidenced by colder fluid being concentrated at the mantle base. Shown in Figure le is the non-adiabatic radial temperature profile. Below the superadiabatic upper thermal boundary layer, temperatures drop subadiabatically by about 300 degrees from the upper mantle to the CMB. Figure $1 \mathrm{~b}$ shows a model identical to the reference case, except that we have stiffened the lower mantle by a factor of 40 relative to the upper mantle viscosity $\left(2 \times 10^{22} \mathrm{~Pa} \mathrm{~s}\right)$, as suggested by studies of the geoid [Ricard et al., 1993]. Subadiabaticity (Figure 1f) is comparable to the reference case, except for a region near the CMB where temperatures increase somewhat steeper than the adiabat. An isoviscous convection model with $50 \%$ core heating is shown in Figure 1c. Note that this core heat flux is significantly larger than estimates for the Earth [Davies 1988], and that it is in addition to the internal heating rate which remains unchanged from the reference case. The temperature field shows numerous hot upwellings from the CMB in addition to cold downwellings from the surface. The radial temperature profile (Figure $1 \mathrm{~g}$ ) reveals that mantle subadiabaticity is reduced to half its value in the reference case, or about 150 degrees. A model combining a lower mantle viscosity in- 

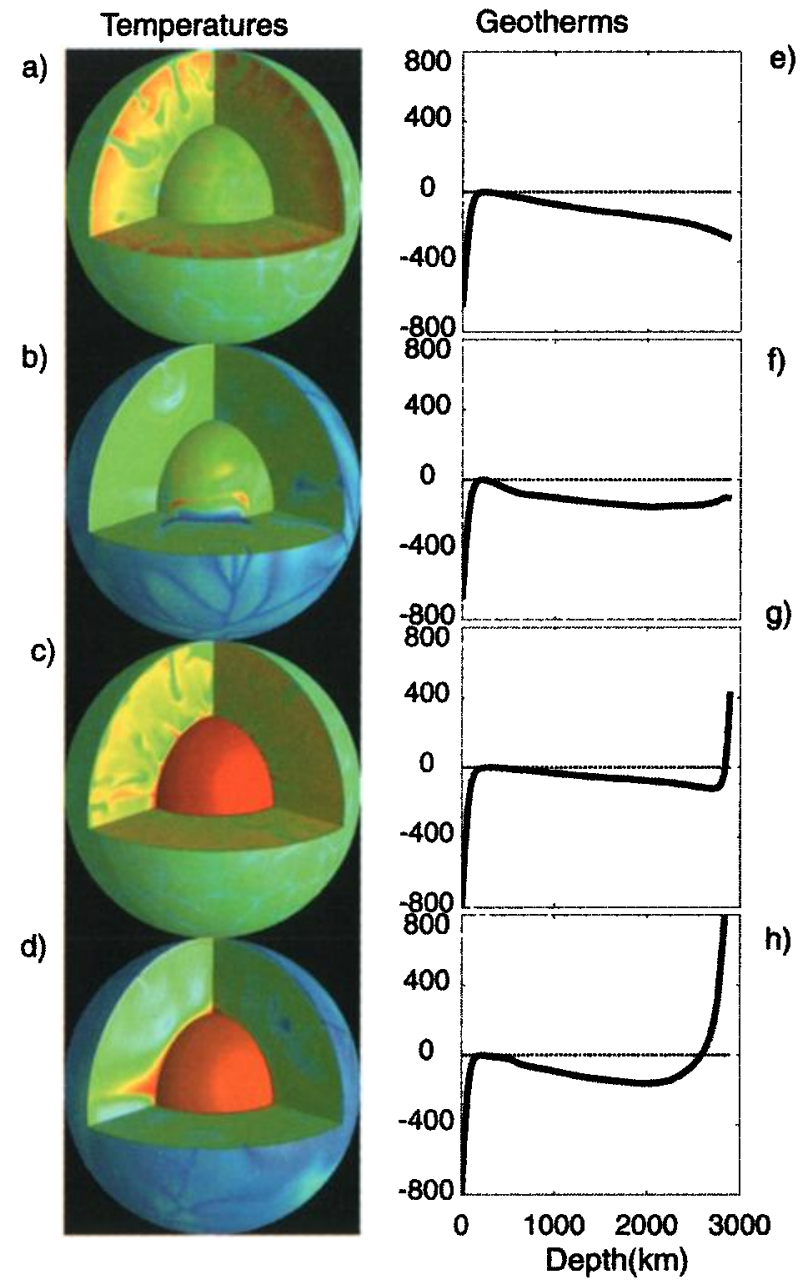

Figure 1. a) Non-adiabatic temperatures for the isoviscous, purely internally heated reference case. Blue is cold and red is hot. The top $100 \mathrm{~km}$ of the mantle is removed. Cold fluid is concentrated near the mantle base. b) Same as (a) except that lower mantle viscosity has been increased by a factor of $40 . \mathrm{c} / \mathrm{d}$ ) Same as $(\mathrm{a} / \mathrm{b})$ except for the addition of $50 \%$ core heating. (e)-(h) Non-adiabatic geotherms for cases (a)-(d). Superadiabaticity is concentrated into narrow thermal boundary layers. The geotherm is subadiabatic for the intervening region.

crease (factor 40 ) and $50 \%$ core heating with the internal heat production of the reference calculation is shown in Figure 1d. In this hybrid model hot mantle upwellings from the CMB are swept into a few major plumes due the longwavelength planform induced by viscosity layering [Bunge et $a l ., 1996]$, while most of the lower mantle away from plumes appears to be relatively cold. This observation is borne out in the radial temperature profile (Figure $1 \mathrm{~h}$ ), which shows a non-adiabatic temperature gradient of $-0.1 \mathrm{degree} / \mathrm{km}$ before reaching a broad thermal boundary layer at the CMB.

\section{Density profiles and seišmic inhomogeneity}

The modeled geotherms may be converted into density profiles to estimate the subadiabatic effect on mantle density. In Figure 2a we calculate the lower mantle excess density relative to the adiabatic reference density profile in a mineralogic model of pyrolite composition [Matas, 1999]. As expected, the cold geotherms steepen the density increase with depth for all four models shown in Figure 1. However, the anomalous excess density remains below $0.2 \%$ due to the small value of the thermal expansivity under lower mantle conditions $\left(1.5 \times 10^{-5} \mathrm{~K}^{-1}\right)$ [Chopelas $\&$ Boehler, 1992; Duffy \& Ahrens, 1993]. The subadiabatic effect on the isentropic bulk modulus $K_{s}$ (Figure 2b) is somewhat larger, with excess values of $K_{s}$ approaching one percent. To go one step further in comparing our results with seismic observations, we compute Bullen's stratification parameter $\eta$ [Bullen, 1963] in Figure 3. $\eta$ measures departures from the Adams-Williamson relation, and is exactly one for adiabatic and chemically homogeneous regions. From Figure 3 we identify three distinct regimes for $\eta$. In the thermal
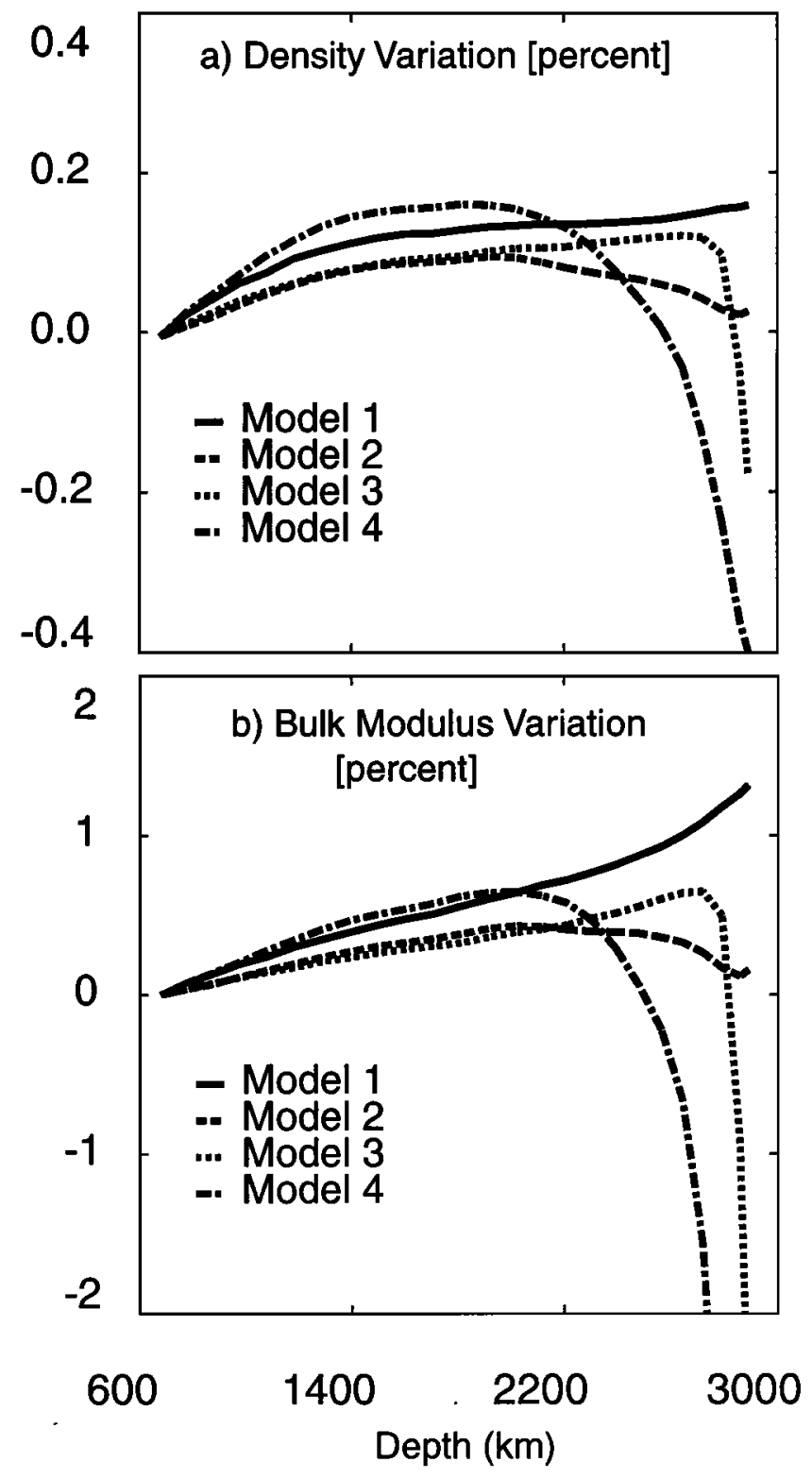

Figure 2. a) Lower mantle excess density in a pyrolite model relative to the adiabat for the four geotherms in Figure 1. Density variations remain below $0.2 \%$ due to the small value of lower mantle thermal expansivity. b) Same as a), but for the isentropic bulk modus $K_{s}$. 
boundary layers near the top and bottom of the mantle $\eta$ is substantially smaller than one, as expected. There is also a sharp increase in the upper mantle for models with layered viscosity due to the strongly subadiabatic geotherm in the low viscosity zone. For the rapidly convecting interior of the lower mantle, we find $\eta$ is about 1.01 in agreement with results obtained by Matyska \& Yuen [2000] for 2D convection.

\section{Discussion}

The magnitude of mantle non-adiabaticity implied by the convection models is significant. Observational evidence [Davies, 1988] suggests predominantly internal mantle heat generation with an additional component arising possibly from secular cooling [Davies, 1980], which would act as a further source of internal heat. We explore the consequences in Figure 4, where we show absolute lower mantle temperatures tied to a temperature of $1800 \mathrm{~K}$ at the $660 \mathrm{~km}$ depth ringwoodite/perovskite+oxide phase change for two end-member calculations. The geotherm computed from the reference model (Figure 1a) increases by about 400 degrees through the lower mantle, with most of the lower mantle being stably stratified in agreement with earlier results obtained by Jarvis $\&$ McKenzie [1980]. The temperature inferred for the CMB is $2200 \mathrm{~K}$ in this case. Setting the core temperature to a geophysically more plausible value (3800 K) [Boehler, 1996] results in 50\% heating from the core even for the more realistic convection model with a high viscosity lower mantle (Figure 1d) due to the sharp temperature drop of nearly $1600 \mathrm{~K}$ across the thermal boundary layer. This modeled heat flux is substantially higher than the core

\section{Seismic Inhomogeneity Parameter}
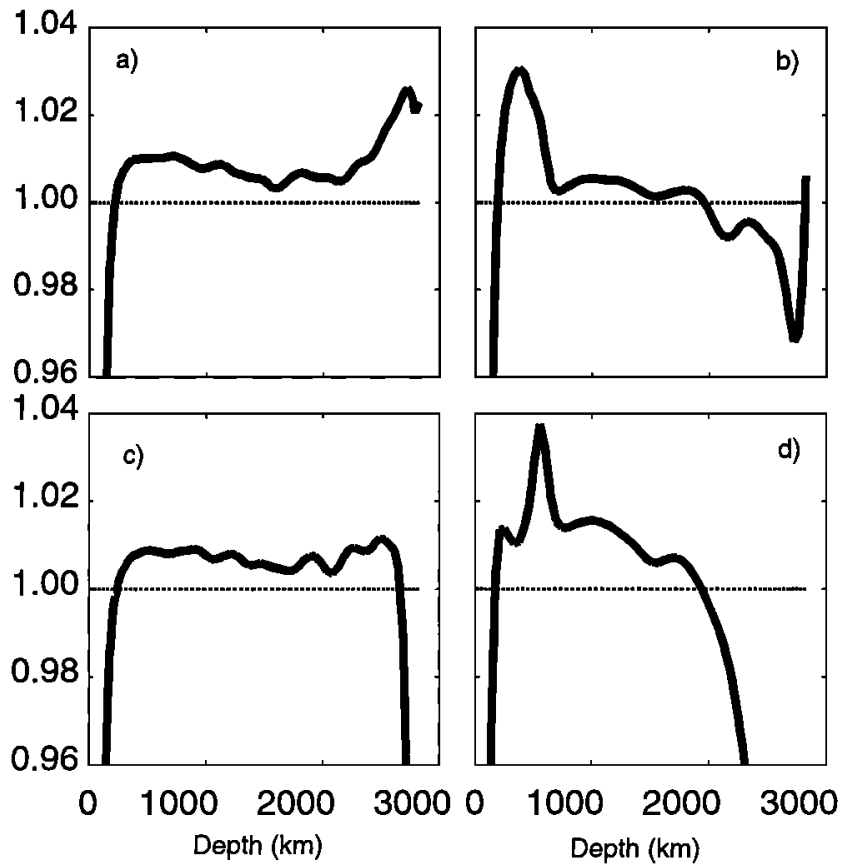

Figure 3. (a)-(d) Seismic inhomogeneity parameter $\eta$ (see text) for the four models in Fig. 1a-d. $\eta$ is defined as $\eta=-\frac{\phi}{\rho g} \frac{d \rho}{d r}$, where $\rho$ is density, $r$ is radial distance from the Earth's center, $g$ is the acceleration due to gravity, and $\phi\left(=\frac{K_{3}}{\rho}\right)$ is the seismic parameter.

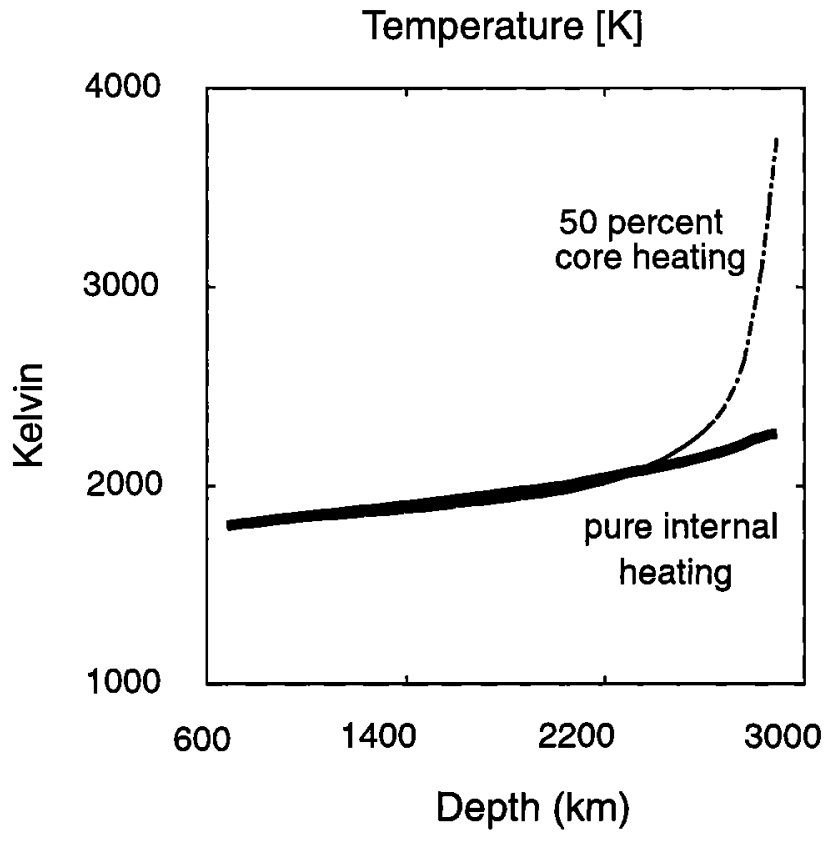

Figure 4. Lower mantle geotherms for the isoviscous, bottom insulated reference model (Fig. 1a), and the stratified viscosity case with $50 \%$ heating from the core (Fig. 1d). A geothermal gradient of about 0.2 degree $/ \mathrm{km}$ characterizes the lower mantle away from the thermal boundary layer at the CMB.

heat flux inferred from mantle hotspots [Davies, 1988]. A chemically distinct layer at the bottom of the mantle would lower the core heat flux by distributing the temperature drop across an additional thermal boundary layer. It would also help to reduce the high excess temperature of mantle plumes [Farnetani, 1997] suggested by our isochemical calculations. The existence of this layer appears likely from geochemical [Hofmann, 1997] and seismic considerations [van der Hilst \& Karason, 1999], and has been explored in dynamic models [Christensen \& Hofmann, 1994; Kellogg et al., 1999; Coltice \& Ricard, 2000]. A seismological consequence of our result is that homogeneous regions in the lower mantle should appear otherwise, with $\eta \sim 1.01$, and that $\eta$ should be as low as $\eta \sim 0.92$ for a broad thermal boundary layer region in the bottom $500 \mathrm{~km}$ of the mantle (Figure 3). Seismic observations of $\eta$ are resolved to about $2 \%$ in the lower mantle [Masters, 1979], which suggests that constraints on $\eta$ should be improved to infer the mantle geotherm.

\section{References}

Boehler, R., Melting temperature of the Earth's mantle and core, Earth's thermal structure, An. Rev. Earth Planet. Sciences, 24, 15-24, 1996.

Bullen, K.E., An index of degree of chemical inhomogeneity in the Earth, Geophys. J. Int., 7, 584-592, 1963.

Bunge, H.-P., M.A. Richards and J.R. Baumgardner, A sensitivity study of three-dimensional spherical mantle convection at $10^{8}$ Rayleigh number: Effects of depth-dependent viscosity heating mode, and an endothermic phase change, J. Geophys. Res., 102, 11,991-12,007, 1997.

Bunge, H.-P., M.A. Richards, and J.R. Baumgardner, Effect of depth-dependent viscosity on the planform of mantle convection, Nature, 379, 436-438, 1996.

Bunge, H.-P., and J.R. Baumgardner, Mantle convection modeling on parallel virtual machines, Computers in Physics, 9 , 207-215, 1995. 
Birch, F., Elasticity and constitution of the Earth's interior, $J$. Geophys. Res., 57, 227-286, 1952.

Chopelas, A., and R. Boehler, Thermal expansivity in the lower mantle, Geophys. Res. Lett., 19, 1,983-1,986, 1992.

Christensen, U.R., and A.W. Hofmann, Segregation of subducted oceanic crust in the convecting mantle, J. Geophys. Res., 99, 19,867-19,884, 1994.

Coltice, N., and Y. Ricard, Geochemical observations and one layer mantle convection, EPSL, 174, 125-137, 1999.

Davies, G.F., Ocean bathymetry and mantle convection, 1. Largescale flow and hotspots, J. Geophys. Res., 93, 10,467-10,480, 1988.

Davies, G.F., Thermal histories of convective earth models and constraints on radiogenic heat production in the earth, J. Geophys. Res., 85, 2,517-2,530, 1980.

Duffy, T.S., and T.J. Ahrens, Thermal expansion of mantle and core materials at very high pressures, Geophys. Res. Lett., 20, 1,103-1,106, 1993

Dziewonski, A.M., and D.L. Anderson, Preliminary reference Earth model, Phys. Earth Planet. Inter., 25, 297-356, 1981.

Farnetani, C.G., Excess temperature of mantle plumes: the role of chemical stratification across D", Geophys. Res. Lett., 24 , 1,583-1,586, 1997.

Giardini, D., X.D. Li, and J.H. Woodhouse, 3-Dimensional structure of the Earth from splitting in free-oscillation spectra, $\mathrm{Na}$ ture, 325, 405-411, 1987.

Hofmann, A.W., Mantle geochemistry: The message from oceanic volcanism, Nature, 385, 219-229, 1997.

Jarvis, G.T., and D.P. McKenzie, Convection in a compressible fluid with infinite Prandtl number, J. Fluid Mech., 96, 515$583,1980$.

Jeanloz, R., and S. Morris, Is the mantle geotherm subadiabatic, Geophys. Res. Lett., 14, 335-338, 1987.

Kellogg, L.H., B.H. Hager, and R.D. van der Hilst, Compositional stratification in the deep mantle, Science, 283, 1,881-1,884, 1999.

Masters, G., Observational constraints on the chemical and thermal structure of the Earth's deep interior, Geophys. J. R. astr. Soc., 57, 507-534, 1979.

Matas, J., Modélisation thermochimique des propriétés de solides à hautes températures et à hautes pressions. Applications géophysiques, 176 pp., Ecole Normale supérieure de Lyon, January 1999.

Matyska, C. and D. A. Yuen, Profiles of the Bullen parameter from mantle convection modeling, EPSL, 178, 39-46, 2000.

Parmentier, E.M., C. Sotin, and B.J. Travis, Turbulent 3-D thermal convection in an infinite Prandtl number, volumetrically heated fluid: implications for mantle dynamics, Geophys. J. Int., 116, 241-251, 1994.

Ricard Y., M. A. Richards, C. Lithgow-Bertelloni and Y. Le Stunf, A geodynamic model of mantle density heterogeneity, J. Geophys. Res., 98, 21,895-21,909, 1993.

Shankland, T.J., and J.M. Brown, Homogeneity and temperatures in the lower mantle, Phys. Earth Plant. Inter., 38, 51-58, 1985.

Tackley, P.J., D.J. Stevenson, G.A. Glatzmaier, and G. Schubert, Effects of multiple phase transitions in three-dimensional spherical models of convection in Earth's mantle, J. Geophys. Res., 99, 15,877-15,901, 1994.

Van der Hilst, R.D., and H. Karason, Compositional heterogeneity in the bottom 1000 kilometers of Earth's mantle: Toward a hybrid convection model, Science 283, 1,885-1,888, 1999.

Van der Hilst, R.D., S. Widiyantoro, and E.R. Engdahl, Evidence for deep mantle circulation from global tomography, Nature 386, 578-584, 1997.

Hans-Peter Bunge, Department of Geosciences, Guyot Hall Princeton University, Princeton, NJ 08544, USA (email: bunge@princeton.edu)

Yanick Ricard, Department Sciences de la Terre, ENS de Lyon, 46 Alle d'Italie 69364 LYON Cedex 07, France (e-mail: ricard@ens-lyon.fr)

Jan Matas, Department of Geology \& Geophysics, UC Berkeley, Berkeley, CA 94720, USA (e-mail: matas@uclink.berkeley.edu)

(Received June 6, 2000; revised October 24, 2000; accepted November 6, 2000.) 